\title{
EFFICACY OF FIXED BED OZONATION TREATMENT TO CONTROL INSECTS IN STORED BULK GRAIN
}

\author{
C. A. Campabadal, D. E. Maier, L. J. Mason
}

\begin{abstract}
Scale-up demonstration trials were conducted at the pilot bin facility of the Purdue University Post-Harvest Education and Research Center in June 2005, August 2006, July 2007, and October 2008 with conventional yellow maize and at a popcorn storage facility in July 2005 and 2006. The primary objective of these trials was to determine the efficacy of ozonation to control insect pests without affecting end-use quality. The setup consisted of generating ozone at a constant rate with commercially available generators, introduction in the headspace, drawdown to the plenum with a fan with a minimum air velocity through the grain of $0.03 \mathrm{~m} / \mathrm{s}$, re-circulation back into the headspace or exhausting from the plenum into another bin. Ozonation was done to attain an ozone concentration of $50 \mathrm{ppm}$ in the plenum to be maintained for a period of $72 \mathrm{~h}(3,600 \mathrm{ppm}-\mathrm{h})$. When this concentration was not achieved, an ozone concentration-time product of 3,600 ppm- $h$ was aimed for extending the time to expose the grain mass to the same treatment effect to achieve 100\% insect mortality. The trials were performed using insect bioassays with adults of maize weevil (MW) and red flour beetle (RFB). Insect mortality was essentially $100 \%$ for both MW and RFB. The concept of two phases of ozonation and the airflow rates needed to achieve the required treatment levels of 3,600 ppm-h were investigated. The trials at the popcorn facility confirmed that end-use parameters of popcorn were not affected.
\end{abstract}

Keywords. Ozonation, Maize, Popcorn, Fumigation, Stored-product insect pests.

$\mathrm{I}$ nsects and molds cause significant damage to grain each year producing economic losses that affect farmers, elevator managers, and processors throughout the world (Leesch, 2002). Stored grain protection relies heavily on the use of chemicals like methyl bromide and phosphine to control pests. Due to the increased concern over the use of post-harvest chemicals worldwide, the phase out of methyl bromide under the Montreal Protocol (UNEP, 1995) and the phosphine resistance of insects, there is much interest in the development and use of non-chemical treatments such as temperature extremes, modified atmospheres, heat treatment of empty structures, physical exclusion, nonchemical protectants, biological controls, and ozonation to control stored product pests.

Ozonation has been tested for its efficacy in insect control in laboratory experiments and field trials using fixed bed systems with no grain movement and a steady flow of ozone. In laboratory experiments, several concentration-time products (CTP) have been investigated for insect mortality. Rozado et al. (2008) observed 95\% mortality for adult maize weevil (MW) with $1,188 \mathrm{ppm}-\mathrm{h}$

Submitted for review in August 2012 as manuscript number FPE 9888; approved for publication by the Food \& Process Engineering Institute of ASABE in June 2013.

The authors are Carlos A. Campabadal, Program Specialist and Instructor, Dirk E. Maier, ASABE Member, Department Head and Professor, Department of Grain Science and Industry, Kansas State University, Manhattan, Kansas; and Linda J. Mason, Professor, Department of Entomology, Purdue University, West Lafayette, Indiana. Corresponding author: Carlos A. Campabadal, 201 Shellenberger Hall, Manhattan, KS 66506; phone: 785-532-3187; e-mail: campa@ ksu.edu. and for adult red flour beetle (RFB) with 3,210 ppm-h. Pereira et al. (2008) observed 95\% mortality for adult RFB with 7,590 ppm-h at $20^{\circ} \mathrm{C}$. Leesch (2002) observed $100 \%$ mortality for adult confused flour beetle (CFB) with 5,400 ppm-h, but also observed $100 \%$ mortality for adult Indian meal moth (IMM) with only $300 \mathrm{ppm}-\mathrm{h}$. Similar results of $100 \%$ insect mortality with low ozone CTP at $292.5 \mathrm{ppm}-\mathrm{h}$ were also observed by Erdman (1980) for adult RFB and CFB. Strait (1998) achieved 100\% mortality for adult MW, RFB, and CFB with 3,600 ppm-h. In field trials, Kells et al. (2001) used a CTP of at least 3,600 ppm-h and consistently achieved $92 \%$ to $100 \%$ mortality for adult MW and adult RFB in their studies. In field trials, Bonjour et al. (2008, 2011) observed $100 \%$ mortality of adult RFB with a CTP of 4,800 ppm-h and of adult rice weevil (RW) with $2,400 \mathrm{ppm}-\mathrm{h}$. Based on the limited literature available, it appears that the CTP for effective insect control varies by species and life stages, and requires further investigation. However, based on these laboratory experiments and field trials, it can be assumed that aiming for a CTP of at least $3,600 \mathrm{ppm}-\mathrm{h}$ should result in $90 \%$ to $100 \%$ mortality of adult-stored product insects. This became the treatment target for the trials undertaken in this study.

In laboratory trials, McDonough et al. (2011b) using treatment chambers without grain determined that a CTP of at least 5,400 ppm-h was needed to achieve $100 \%$ mortality of pupae and eggs of RFB and eggs of IMM. For the adults' stages it required a CTP of 3,600 ppm-h for MW and 1,800 ppm-h for RW. Hansen et al. (2012) achieved $100 \%$ mortality for adult saw-toothed grain beetle (SGB), Lesser Grain Borer (LGB), RFB, CFB, and IMM using a CTP of 5,040 ppm-h and $85 \%$ mortality for adult bread 
beetle $(\mathrm{BB})$ in research trials using treatment chambers without grain. Also, their results indicated that a CTP of $25,920 \mathrm{ppm}-\mathrm{h}$ will be necessary to control all internal stages of granary weevil (GW), RW, and MW. Holmstrup et al. (2011) showed that in laboratory trials treating adult and large larvae RFB resulted in $100 \%$ mortality after treatment for $24 \mathrm{~h}$ at $40 \mathrm{ppm}$. This is equivalent to a CTP of $960 \mathrm{ppm}-$ $\mathrm{h}$ and four to five times lower compared to the CTPs found in earlier research trials which also achieved $100 \%$ mortality for RFB. No differences in the treatment process developed by Holmstrup et al. (2011) were found compared to the other treatment processes except that the insects were treated in shallow plastic containers without grain. McDonough et al. (2011a) found that there was no difference in insect mortality when treating MW and RFB using very high CTP values of $258,120 \mathrm{ppm}$-h during a short time period using humidified versus dried ozone in a modified screw conveyor handling maize at low rotational speeds.

Additionally, ozonation has several advantages compared to available fumigants that make its usage attractive as an alternative for pest control by the food grain industry. The main advantages are: (1) Ozone is a powerful oxidant (fifth in thermodynamic oxidation potential). Therefore, it will react with a sterilization effect against many organic materials present on the surface of grain kernels (Graham, 1997; Khadre et al., 2001). (2) Ozone application has been approved as generally recognized as safe for sanitation and sterilization purposes (FDA, 2001) and it has been regulated as a non-chemical and environmentally friendly alternative (EPA, 1999) in the food processing industry. (3) Ozone decomposes rapidly into oxygen due to its instability characteristics, therefore leaving no residue (Khadre et al., 2001; Mendez et al., 2003). Its half-life time can be up to $24 \mathrm{~h}$ in still air, but much less in flowing air depending on its air temperature and relative humidity (McClurkin, 2009). (4) Ozone can be generated on-site so no storage, transportation, or disposal of spent ozone is needed (Strait, 1998). (5) Ozone treatment for stored product pests external to grain kernels showed the same mortality results as compared to phosphine fumigation (Strait, 1998; Kells, 2001). (6) Phosphine-resistant stored product insects were susceptible to ozone treatment without development of cross-resistance (Sousa et al., 2008).

The basic setup for a fixed bed ozonation system consists of generating ozone at a constant rate with commercially available generators, introduction into the headspace and drawdown through the grain mass to the plenum, or introduction into the plenum and movement through the grain mass to the headspace depending on the characteristics of the storage bin and the airflow direction of the fan (suction or push). Each fixed bed system contains a re-circulation loop of ozone back into the headspace or an exhausting system of ozone from the plenum into another bin. Field experimental trials have used a recirculation system (Kells et al., 2001) or a similar setup based on the closed loop fumigation (CLF) system design developed by Noyes et al. (2002). The exhausting system into another bin is used when the recycling system is difficult to implement due to the physical constraints of a larger size bin. Residual ozone not yet reacted with the grain mass after reaching the plenum is exhausted through a flexible duct into a nearby bin. This assures that ozone is not exhausted into the environment around the treated bins.

Fixed bed systems have several characteristics based on the behavior of ozone when it is applied to grain. The initial ozonation treatment of a grain mass takes more time to complete than subsequent treatments of the same grain mass (as long as it is not moved and recontaminated with dust, etc.) because ozone reacts with the cell structures of mold spores, insects, bacteria, and other biological matter adhering to grain kernel surfaces and contained within the grain mass. Completion of the sterilizing ozonation effect depends on the quantity of biological matter to be reacted with, the quantity of ozone available to react, and the supply of ozone to complete the reaction process throughout the grain mass within a timely manner. This stage is called Phase 1. After this initial reaction process, ozone will move faster and more freely through the grain mass and steadily increase in concentration. The initial sterilization phase lasts until the target treatment is reached in the exit layer of the grain mass. Other researchers have used a similar concept but called it passivation time, which is the time required by ozone to reach a steady state level during treatment in a fixed bed system (Hardin et al., 2010). Once the ozone reaches the desirable concentration, ozonated air must continue to be moved through the grain mass and kept constant for the needed number of days to reach the CTP to complete the ozonation treatment (Kells et al., 2001). This stage is called Phase 2. It has been reported that a minimum air velocity of $0.03 \mathrm{~m} / \mathrm{s}$ must move through the grain mass to achieve an optimal ozone concentration and treatment effect (Kells et al., 2001; Mendez et al., 2003) during Phase 1 and a minimum air velocity of $0.02 \mathrm{~m} / \mathrm{s}$ during Phase 2 (Kells et al., 2001). The primary objective of this research was to undertake scale-up demonstration trials for the fixed bed ozonation treatment system and to confirm efficacy to control insect pests in stored bulk grain without affecting end-use quality.

\section{Materials AND Methods}

\section{FIXED BED OZONATION WITH RECIRCULATION SYSTEM}

One set of trials was conducted at the pilot bin facility of the Purdue University Post-Harvest Education and Research Center (PHERC) in June 2005, August 2006, July 2007, and October 2008 using four bins each containing 9.6 tonnes of conventional yellow maize. Each of the four grain bins had a $2.75 \mathrm{~m}$ diameter and a $2.9 \mathrm{~m}$ eave height with a grain depth of $2.2 \mathrm{~m}$. The bins were not airtight in order to represent typical grain storage conditions and were treated at the same time. During the first ozonation trial in June 2005, Bins A and B had $0.037 \mathrm{~kW}(1 / 20 \mathrm{hp})$ axial fans and Bin $\mathrm{C}$ a $0.25 \mathrm{~kW}(1 / 3 \mathrm{hp})$ axial fan generating air velocities of less than 0.01 and $0.06 \mathrm{~m} / \mathrm{s}$, respectively. For the second ozonation trial in June 2005 and the trials in August 2006, July 2007, and July 2008, all three bins had $0.25 \mathrm{~kW}(1 / 3 \mathrm{hp})$ axial fans generating air velocities of $0.06 \mathrm{~m} / \mathrm{s}$. Those trials were part of a larger study comparing 
four pest management strategies during multi-year storage of maize (i.e., automated aeration with ambient air, intermittent grain chilling, automated aeration with intermittent ozonation, and no aeration). The average moisture content of the maize in the three bins was $12 \%$ w.b. in the first treatment year (2005) and 9.5\% in the last treatment year (2008). In all trials, the goal was to attain an ozone concentration of $50 \mathrm{ppm}$ in the plenum and to maintain that for a period of 3 days using a recirculation system (fig. 1) to recover the ozone exiting at the bottom of each bin (plenum) and injecting it back into the top of each bin (headspace). This recirculation system was based on the closed-loop fumigation system developed by Noyes et al. (2002) designed to distribute fumigant evenly through a grain mass inside a bin. This setup eliminated ozone leakage to the environment through the grain bin eave opening, optimized the performance of the ozone generator, and reduced any potential condensation to form on the underside of the bin roof.

\section{FIXED BED OZONATION WITH NON-RECIRCULATION SYSTEM}

A set of trials was conducted at a popcorn storage and processing facility in July 2005 and 2006 using two bins containing each 456 tonnes of popcorn. Each of the two grain bins had a diameter of 10.98 and $7.3 \mathrm{~m}$ eave height with a grain depth of $6.71 \mathrm{~m}$. The bins were not airtight representing typical grain storage conditions. Both trials were performed using an exhaust system (fig. 2) to direct the residual ozone exiting from the plenum into a second nearby bin. This set up was used when the target ozone

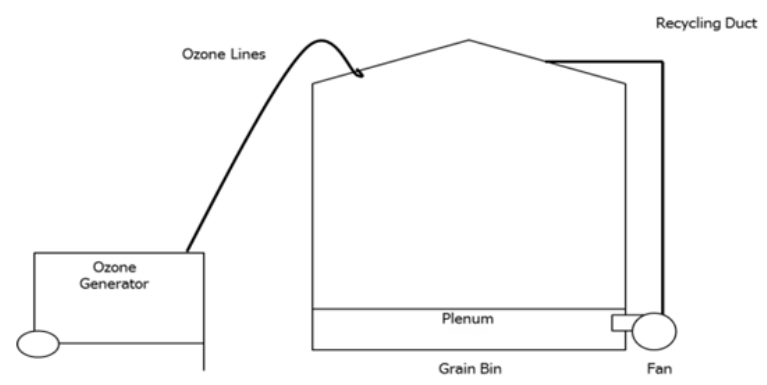

Figure 1. Schematic of fixed bed ozonation with recirculation system for grain bins. concentration of $50 \mathrm{ppm}$ in the plenum could not be reached due to the lack of sufficient ozone producing capacity of the generator for a relatively larger size bin. Therefore, a CTP of 3,600 ppm-h at the plenum was used to adjust the ozonation process over a longer period of time using a lower ozone concentration to achieve 100\% insect mortality (Strait, 1998). This was also used due to the physical and economic limitations of installing an adequate recirculation system in grain bins with capacities larger than 250 tonnes. Similar to the recirculation system set up, it primarily served to eliminate ozone leakage into the environment and optimized the performance of the ozone generator, and reduced any potential condensation to form on the underside of the bin roof.

Popcorn quality after ozonation treatment was quantified by staff of the popcorn processing company and included Metric Weight Volume Test, moisture content using the airoven method for maize (ASABE Standards, 2008), and kernel count. The Metric Weight Volume Test is the standard unit of measurement used in the industry to quantify the potential expansion of a batch of popcorn measured in popcorn yield by volume related to kernel mass in $\mathrm{mL} / \mathrm{g}$ with an optimal range between 40 to $50 \mathrm{~mL} / \mathrm{g}$. In order to have optimal popping, the moisture content should range from $13.5 \%$ to $14.5 \%$ (Ziegler, 2002). The kernel count is a quality parameter used to measure consistency in popcorn kernels. It is the number of kernels per $10 \mathrm{~g}$ of popcorn where the higher number of kernels, the smaller the kernel size will be. The popcorn processing facility uses a target value of 60 kernels as their standard quality.

\section{InSECT MORTALITy QUANTIFICATION}

All trials conducted with conventional yellow maize at the PHERC pilot bin facility and at the popcorn storage and processing facility used insect bioassays to quantify insect mortality at the end of each ozone treatment. The numbers of live and dead insects were counted $24 \mathrm{~h}$ after the bioassays were pulled out from the treatment and control bins. In the trials, placement inside each treatment and control bin consisted of a pair of insect bioassays placed $0.6 \mathrm{~m}$ below the grain surface in each of the four cardinal points and at the center of each grain bin. Also, three pairs

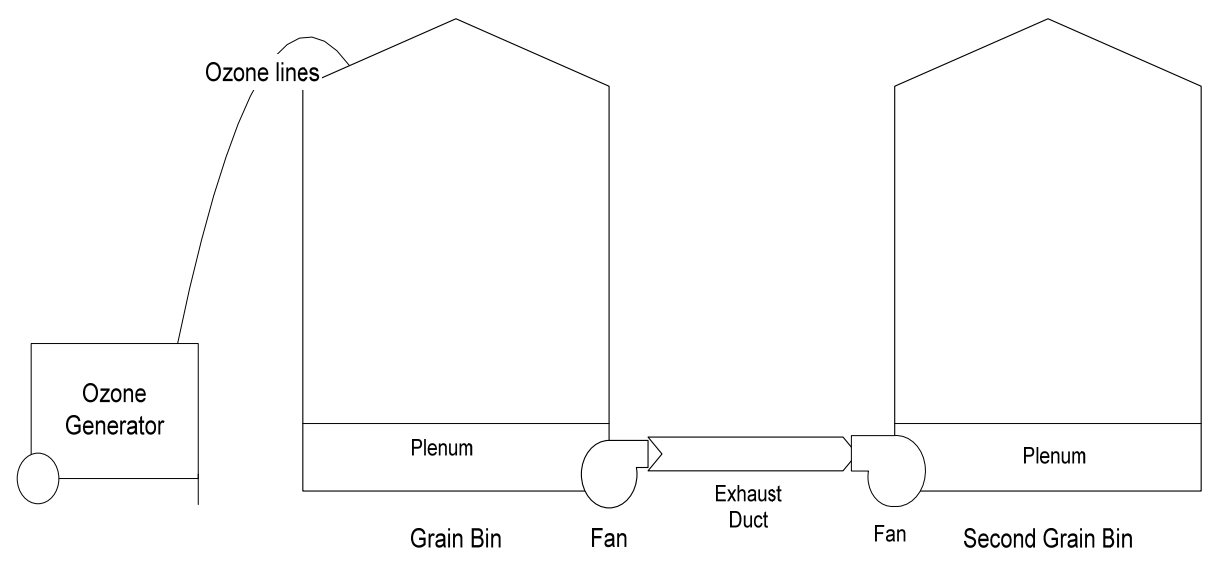

Figure 2. Schematic of fixed bed ozonation with non-recirculation system for grain bins. 
of insect bioassays were located in the plenum of each treatment and control bin. In each pair, one insect bioassay contained $25 \mathrm{MW}$ adults and the other one $25 \mathrm{RFB}$ adults with each one containing $250 \mathrm{~g}$ of untreated maize for insect feeding. Each insect bioassay was prepared using an insect cage made out a PVC pipe with a diameter of 0.076 $\mathrm{m}$ and a length of $0.15 \mathrm{~m}$. For each cage, nylon mesh with $94 \mu \mathrm{m}$ thread diameter was used to seal the ends and allow insect respiration. Insect mortality was averaged across bioassay locations. The insect bioassays placed in control bins were not exposed to any pest control treatment.

In the 2006 trial at the popcorn storage facility after ozonation treatment and insect mortality quantification, the insects and yellow maize from the insect bioassays were placed in mason glass jars with mesh $(94 \mu \mathrm{m}$ thread diameter) type lids for insect respiration. They were held in a growth chamber at $28^{\circ} \mathrm{C}$ and $65 \%$ relative humidity until the first emergence progeny count at 28 days.

\section{Ozone Production and Monitoring System}

For the conventional yellow maize trials, ozone was produced by a four-chamber generator model 97D4 made by $\mathrm{O} 3 \mathrm{Co}$ (Aberdeen, Idaho) with a capacity of $250 \mathrm{~g} / \mathrm{h}$ of ozone. For the popcorn trials, ozone was produced by the four quads (16 chamber) generator model OzoBlast made by $\mathrm{O} 3 \mathrm{Co}$ (Aberdeen, Idaho) with a capacity of $1,000 \mathrm{~g} / \mathrm{h}$ of ozone. Both generators were equipped to produce constant ozone flow without affecting its quality and levels using a pressurized system that heated and filtered the entering ambient air into the generation system in order to supply a dried and constant air temperature to produce the ozone. In all recirculation and non-recirculation system trials, ozone was delivered by introducing it into the top of each bin through a roof vent using $0.025 \mathrm{~m}$ diameter Teflon hoses. It was drawn down from the top of the grain mass with a fan installed at the bottom of the bin to achieve fast and uniform movement of ozone towards the bottom of the grain mass.

Ozone concentration was monitored using an ozone analyzer model IN-2000 made by INUSA (Boston, Mass.) that has a monitoring range from 0 to 2,000 ppm of ozone concentration and an instrument precision of $1 \%$ equal to a minimum ozone concentration reading of $20 \mathrm{ppm}$. The conversion of ozone measured by volume in air is $1 \mathrm{ppm}$ of ozone $=2.14 \mathrm{mgO}_{3} / \mathrm{m}^{3}$. Data from the ozone analyzer was recorded using a data acquisition unit (Hydra logger 2620A, Fluke Everett, Wash.). For each trial, three monitoring lines of equal lengths were placed in the headspace and three in the plenum of each bin.

\section{RESULTS AND DiSCUSSION OzONATION TRIALS WITH CONVENTIONAL YELLOW MAIZE AT PHERC}

Fixed bed ozonation trials were performed at PHERC on the same grain bins with conventional yellow maize maintained from 2005 to 2008 using a minimum air velocity of $0.03 \mathrm{~m} / \mathrm{s}$ based on Mendez et al. (2003). This velocity assures proper ozone movement through a grain mass.

\section{First Ozonation Trial at PHERC in 2005}

In the first set of experiments, the target ozone concentration of $50 \mathrm{ppm}$ in the plenum was not reached in Bins A, B,

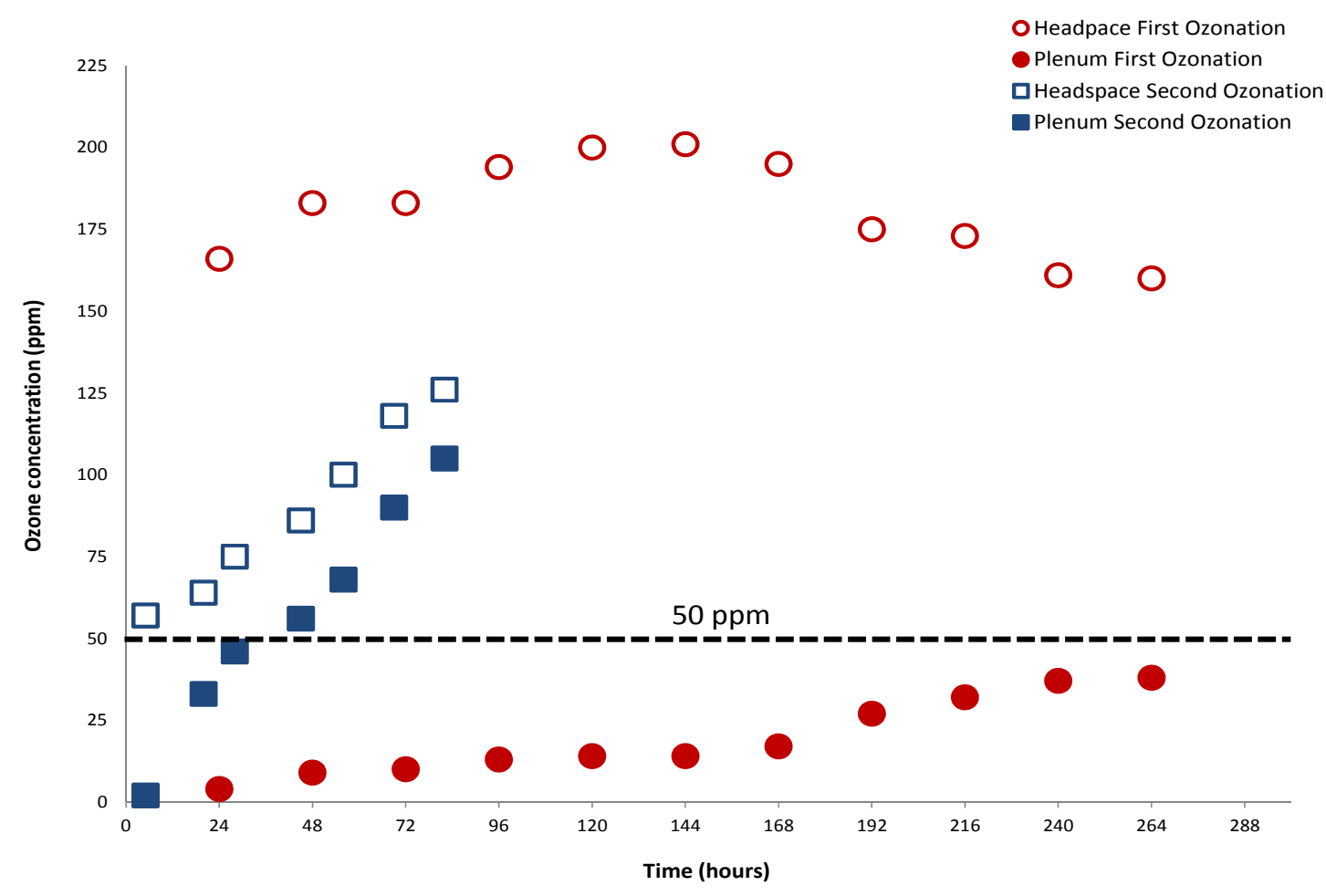

Figure 3. Ozone concentration profile in the headspace and plenum of PHERC Bin A for the first phase ozonation in July 2005 and second phase re-ozonation in September 2005 of yellow maize. For the first phase ozonation the target concentration of 50 ppm in the plenum was not reached, and for the second phase the re-ozonation target concentration of $50 \mathrm{ppm}$ was reached at the plenum after $48 \mathrm{~h}$. 
and $\mathrm{C}$ when ozonated for as long as 11 days (fig. 3). In Bin $\mathrm{A}$, the maximum ozone concentration reached in the plenum was 40 ppm; in Bin B, 45 ppm; and in Bin C, 54 ppm.

The original treatment goal was to reach $50 \mathrm{ppm}$ in the plenum and then hold that concentration for $72 \mathrm{~h}$ in order to achieve $100 \%$ insect mortality based on a CTP of 3,600 $\mathrm{ppm}-\mathrm{h}$ as the needed treatment effect. The effect of time on efficacy for a cumulative CTP of $3,600 \mathrm{ppm}$-h in the plenum was not considered. Therefore, the initial treatment times were rather lengthy because it was thought that $50 \mathrm{ppm}$ had to be reached in the plenum first before the actual treatment effect on insect mortality could be considered. However, when insect mortality was quantified, it was determined that nearly $100 \%$ mortality was achieved in the insect bioassays located $0.6 \mathrm{~m}$ below grain surface in Bins $A$ and $C$ for MW and RFB adults even though $50 \mathrm{ppm}$ had not been reached after $72 \mathrm{~h}$ in either plenum. Subsequently, the ozone concentration data in the plenums of Bins $\mathrm{A}, \mathrm{B}$, and $\mathrm{C}$ were analyzed for their respective cumulative CTPs. Bins A (fig. 4) and C had CTPs of 4,250 and 2,900 ppm-h, respectively, while Bin B had a CTP of 2,110 ppm-h only. Although only Bin A had a CTP greater than 3,600 ppm-h, a CTP of 2,900 ppm-h in Bin C was apparently sufficient to achieve $100 \%$ mortality.

The insect bioassay results (table 1) for the first ozonation showed that $100 \%$ mortality was achieved for both MW and RFB located $0.6 \mathrm{~m}$ below the grain surface. Insect mortality in the plenum during initial ozonation for MW was $91 \%, 36 \%$, and $100 \%$, respectively, for Bins A, B, and $\mathrm{C}$; and for RFB the results were $100 \%, 37 \%$, and $93 \%$ for Bins $\mathrm{A}, \mathrm{B}$, and $\mathrm{C}$, respectively. The unusually low mortality in the plenum of Bin B was caused by the bioassay $\mathrm{s}$ being exposed to water that accumulated in the plenum due to a rainstorm. The bioassays caked over and prevented the ozone from penetrating. Thus, the data collected was excluded from the average calculation which was $95.5 \%$ for MW and $96.5 \%$ for RFB. The control bioassays in Bin D showed on average 3\% and $4 \%$ mortality for MW and RFB, respectively, and for both insect species a standard deviation of 3\%. No substantial difference in insect mortality between MW and RFB adults exposed to the same CTPs was determined in this first set of experiments. The high insect mortality results proved that ozonation could be successfully scaled up from the lab scale (Kells et al., 2001; Mendez et al., 2003) to the pilot scale and utilized as an effective tool for pest control in stored grain.

\section{Second Ozonation Trial at PHERC in 2005}

In the second ozonation (re-ozonation) trial, the $50 \mathrm{ppm}$ target concentration in the plenum was reached after 45,22 , and $36 \mathrm{~h}$ in Bins A (fig. 3), B, and C, respectively, when held for 3 days (Phase 2). During the first ozonation, ozone reacted with the biological matter contained in the grain mass and slowly moved down to the plenum. In the second trial ozone moved through the grain mass at a faster rate than in the first ozonation because ozone had already reacted with biological matter adhering to the grain. In the first ozonation treatment, ozone reached Phase 1 after $120 \mathrm{~h}$ of treatment for Bins A and B due to the lack of minimal airflow provided by the fan that resulted in air velocities of less than $0.01 \mathrm{~m} / \mathrm{s}$, and after $28 \mathrm{~h}$ for Bin $\mathrm{C}$ with air

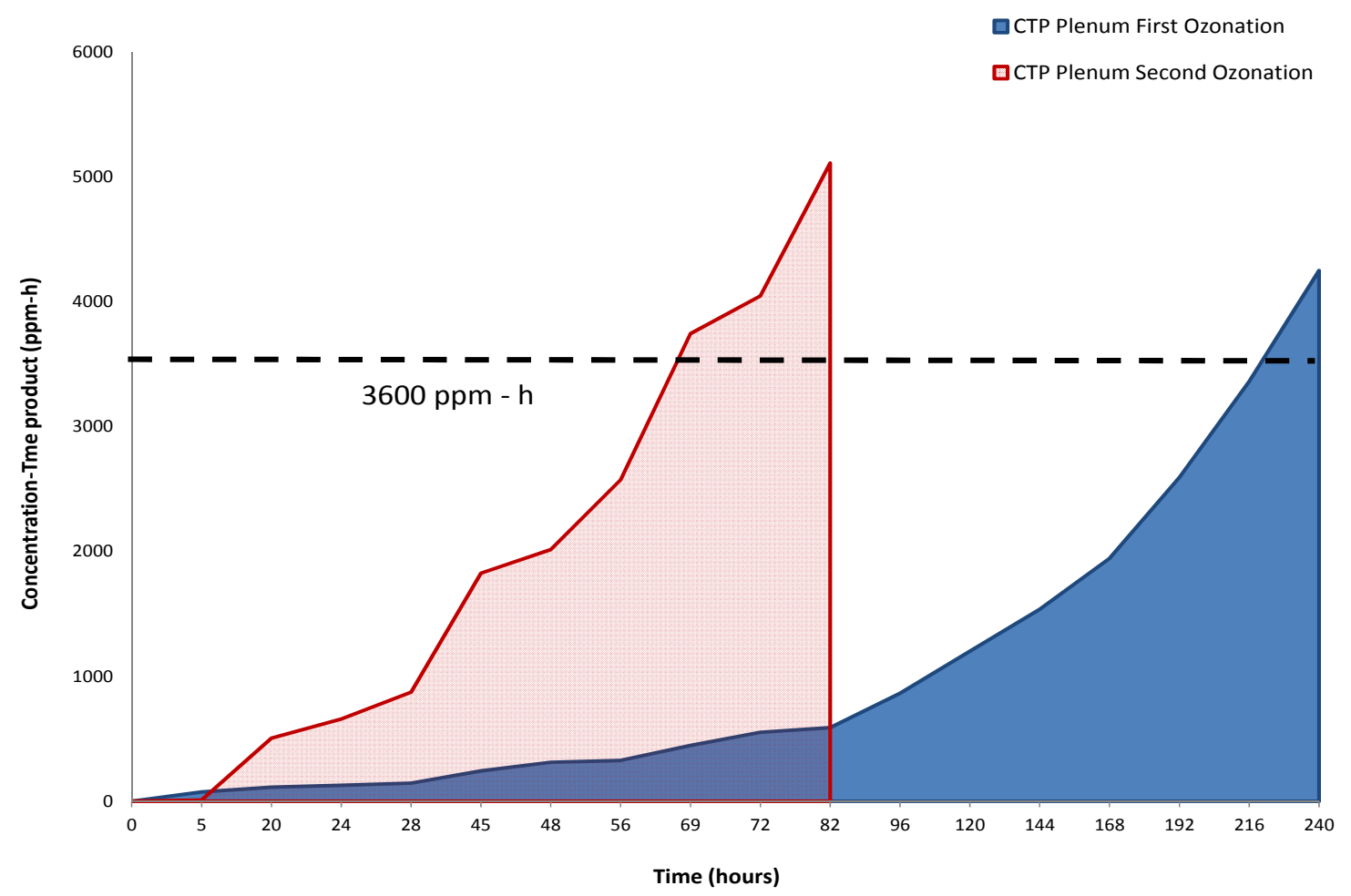

Figure 4. Ozone concentration-time product (CTP) at plenum of PHERC Bin A for the first phase ozonation in July 2005 and for the second phase ozonation of yellow maize in September 2005. For first phase ozonation the target CTP of 3,600 ppm-h was reached after $206 \mathrm{~h}$, and for second phase re-ozonation the target CTP of 3,600 ppm-h was reached after $66 \mathrm{~h}$. 
Table 1. Insect mortality (\%) in bioassays of maize weevil (MW) and red flour beetle (RFB) placed $0.6 \mathrm{~m}$ below the grain surface and in the plenum, and ozone concentration-time product (CTP) during the first ozonation and second ozonation of Bins A, B, and C and in control Bin D in July 2005 and in September 2005, respectively, the ozonation of Bins A, B, and C and in control Bin D in August 2006, and June 2007, and ozonation of Bin B and in control Bin D in October 2008.

\begin{tabular}{|c|c|c|c|c|c|c|}
\hline \multirow[b]{3}{*}{ Bin } & \multirow[b]{3}{*}{ Year } & \multicolumn{5}{|c|}{ Insect Mortality (\%) } \\
\hline & & \multicolumn{2}{|c|}{ MW } & \multicolumn{2}{|c|}{ RFB } & \multirow[b]{2}{*}{$\begin{array}{l}\text { CTP Reached in Plenum } \\
(\mathrm{ppm}-\mathrm{h})\end{array}$} \\
\hline & & $\begin{array}{l}0.6 \mathrm{M} \text { Below } \\
\text { Grain Surface }\end{array}$ & Plenum & $\begin{array}{l}0.6 \mathrm{M} \text { Below } \\
\text { Grain Surface }\end{array}$ & Plenum & \\
\hline \multirow{5}{*}{ A } & $2005^{[\mathrm{a}]}$ & 100 & $91 \pm 12$ & 100 & 100 & 4,250 \\
\hline & $2005^{[\mathrm{b}]}$ & 100 & 100 & $99 \pm 2$ & 100 & 3,900 \\
\hline & 2006 & 100 & 100 & 100 & 100 & 10,880 \\
\hline & 2007 & 100 & 100 & 100 & 100 & 15,790 \\
\hline & $2008^{[\mathrm{c}]}$ & - & - & - & - & - \\
\hline \multirow{5}{*}{$\mathrm{B}$} & $2005^{[\mathrm{a}]}$ & 100 & $36^{[\mathrm{d}]}$ & 100 & $37^{[\mathrm{d}]}$ & 2,110 \\
\hline & $2005^{[\mathrm{b}]}$ & 100 & 100 & 100 & $97 \pm 2$ & 4,115 \\
\hline & 2006 & 100 & 100 & 100 & 100 & 8,350 \\
\hline & 2007 & 100 & 100 & 100 & 100 & 16,540 \\
\hline & 2008 & 100 & 100 & 100 & 100 & 8,500 \\
\hline \multirow{5}{*}{$\mathrm{C}$} & $2005^{[\mathrm{a}]}$ & 100 & 100 & 100 & $93 \pm 6$ & 2,900 \\
\hline & $2005^{[\mathrm{b}]}$ & 100 & 100 & 100 & 100 & 9,000 \\
\hline & 2006 & 100 & 100 & 100 & 100 & 7,930 \\
\hline & 2007 & 100 & 100 & 100 & 100 & 13,820 \\
\hline & $2008^{[\mathrm{c}]}$ & - & - & - & - & - \\
\hline \multirow{5}{*}{ Control } & $2005^{[\mathrm{a}]}$ & $3 \pm 3$ & $3 \pm 3$ & $4 \pm 3$ & $4 \pm 3$ & 0 \\
\hline & $2005^{[\mathrm{b}]}$ & $4 \pm 7$ & $4 \pm 7$ & $3 \pm 3$ & $3 \pm 3$ & 0 \\
\hline & 2006 & $5 \pm 3$ & $5 \pm 3$ & $7 \pm 2$ & $7 \pm 2$ & 0 \\
\hline & 2007 & $7 \pm 1$ & $7 \pm 1$ & $5 \pm 1$ & $5 \pm 1$ & 0 \\
\hline & 2008 & $5 \pm 1$ & $5 \pm 1$ & $6 \pm 1$ & $6 \pm 1$ & 0 \\
\hline
\end{tabular}

[a] First ozonation trial in 2005.

[b] Second ozonation trial in 2005.

[c] No ozonation trials were performed in 2008 for Bins A and C due to no availability of maize for treatment.

[d] The bioassays in Bin B were exposed to water that accumulated in the plenum due to a rainstorm. The bioassays caked over and prevented ozone to penetrate. Therefore, these results were excluded from the calculation of the treatment average.

velocity of $0.06 \mathrm{~m} / \mathrm{s}$. In the second ozonation treatment, all three treated bins used a $0.25 \mathrm{~kW}(1 / 3 \mathrm{hp})$ fan that produced air velocities of $0.06 \mathrm{~m} / \mathrm{s}$ for drawdown of the ozone front through the grain mass. Ozone reached the plenum in less than an hour in each of the three treated bins which was substantially faster than in the first ozonation.

The second ozonation of Bin A showed that the CTP of 3,600 ppm-h (fig. 4) was reached in $66 \mathrm{~h}$ (less than three days) of treatment, which was $140 \mathrm{~h}$ faster than in the first ozonation treatment. For Bins $\mathrm{B}$ and $\mathrm{C}$ a CTP of 3,600 ppm-h CTP was reached in 77 and $50 \mathrm{~h}$, respectively. Given that only in Bin $\mathrm{C}$ the original target concentration of $50 \mathrm{ppm}$ was reached during Phase 1, it was interesting to note that it took only $6 \mathrm{~h}$ to re-establish this concentration in the second ozonation. Apparently, four weeks between the first and second ozonation trials were not enough to allow the treated grain to be re-contaminated with significant amounts of external air carrying dust into the grain bin. Therefore, due to the sterilization effect in the grain mass produced in the first trial, it allowed ozone in the second trial to move quicker through the grain mass and reach the plenum in hours rather than days. Similar results were previously observed by Kells et al. (2001) and Hardin et al. (2010), where Phase 2 was reached faster after interruption between treatments.

The insect bioassay results (table 1) for the second ozonation showed that $100 \%$ mortality was achieved for both MW and RFB located $0.6 \mathrm{~m}$ below the grain surface and in the plenum. The control samples in Bin D showed on average a mortality of $4 \%$ for $\mathrm{MW}$ with a standard deviation of $7 \%$ and an average mortality of $2 \%$ for RFB with a standard deviation of $3 \%$. The CTPs for Bins A, B, and $\mathrm{C}$ (table 1) resulted in values higher than 3,600 ppm-h, especially for Bin $\mathrm{C}$ where ozonation continued for three days after reaching the target concentration of $50 \mathrm{ppm}$. This explained essentially $100 \%$ insect mortality in the bioassays for both treated species. At the same time, it also pointed to the validity of a minimum CTP of 3,600 ppm-h for ozonation treatment.

\section{Ozonation Trials with Conventional Yellow Maize at PHERC in 2006}

The 2006 trials were performed in the same grain bins with the same maize used in the 2005 trials. The target ozone concentration of $50 \mathrm{ppm}$ in the plenum for all three bins (fig. 5) was reached after three days of ozonation (Phase 1) and was subsequently held for three days (Phase 2 ). Despite the fact that the same maize was ozonated twice in 2005, the Phase 2 behavior was not immediately evident after ozonation started as had been expected. During the second ozonation trial in 2005, Phase 2 behavior was evident in Bin $\mathrm{C}$ after $36 \mathrm{~h}$ at an air velocity of $0.06 \mathrm{~m} / \mathrm{s}$. While grain was not moved in or out of the bin, the grain was aerated between the second ozonation in September 2005 and the third ozonation in August 2006. Apparently, sufficient new organic material (mold spores, insects, dust, etc.) had accumulated in the bins in between to somewhat delay previously established Phase 2 conditions of the stored grain. After the first three days, treatment was stopped for $30 \mathrm{~h}$ due to unexpected maintenance of the ozone generator. When ozonation was restarted, the $50 \mathrm{ppm}$ ozone concentration was reached in the plenum in less than an hour for Bins A and B, but for unknown reasons took $25 \mathrm{~h}$ in Bin C. Once ozonation was restarted, Phase 2 was 


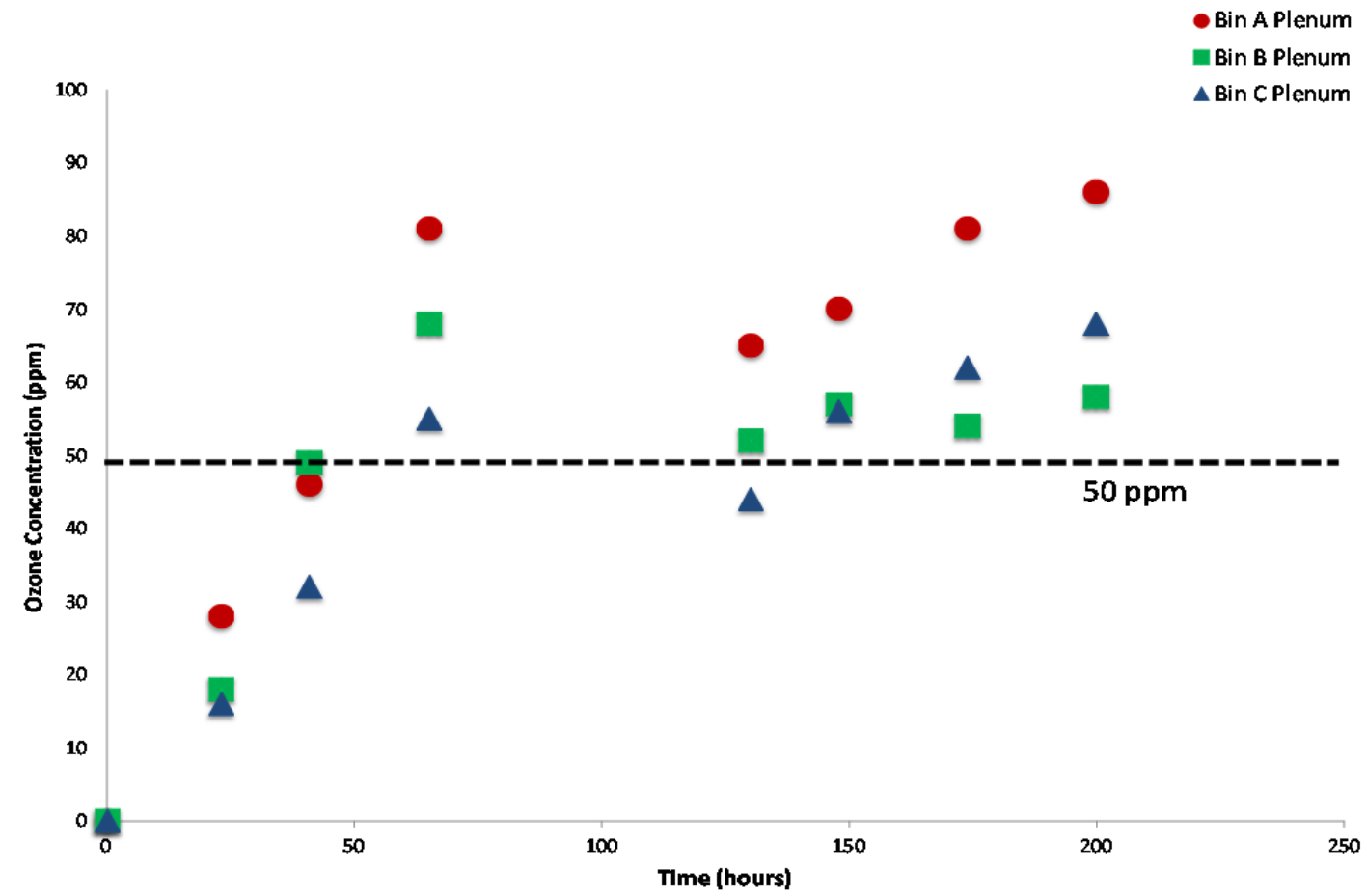

Figure 5. Ozone concentration profile in the plenum of PHERC Bins A, B, and C for ozonation of yellow maize in August 2006. Target ozone concentration of $50 \mathrm{ppm}$ was first reached after 45, 44, and $53 \mathrm{~h}$ in the plenum of Bins $\mathrm{A}, \mathrm{B}$, and C, respectively.

maintained for three days in Bin $\mathrm{C}$ and four days in Bins $\mathrm{A}$ and $\mathrm{B}$. At the time our research focus was not yet on taking advantage of the effect of a cumulative CTP.

The ozone concentration in the headspace for all three bins increased until the third day of treatment. Subsequently, the ozone concentration essentially remained constant at 160,80 , and $50 \mathrm{ppm}$ in Bins A, C, and B, respectively. The reason for the difference in the headspace concentrations of the three bins is not apparent. The most obvious cause may have been an uneven distribution of ozone from the generator through the tubes and valves that should have been better regulated during the experiment.

The insect bioassays located in the plenum and $0.6 \mathrm{~m}$ below the grain surface for the 2006 trial for all three grain bins (table 1) showed that $100 \%$ mortality was achieved for MW in both locations and all three bins. Mortality for RFB averaged $99 \%$ at $0.6 \mathrm{~m}$ below the grain surface and $100 \%$ in the plenum. The control insect bioassays located in Bin $\mathrm{D}$ resulted in insect mortalities for $\mathrm{MW}$ of $5 \%, 3 \%$, and $8 \%$, and for RFB of $7 \%, 9 \%$, and $5 \%$ for Bins $\mathrm{A}, \mathrm{B}$, and C, respectively. These low insect mortalities in the control bins for MW and RFB showed that mortality in the bioassays of the ozone-treated bins were not caused by warm weather conditions during the summer. Due to the efficacy of the ozone treatment, it was not necessary to conduct a reozonation of the bins in 2006. The previously suggested CTP by Strait (1998) of 3,600 ppm-h was achieved and substantially exceeded by two to three times in the treated bins during the trial. Subsequent insect trap counts did not indicate substantial reinfestation.

\section{Ozonation Trials with Conventional Yellow Maize at PHERC in 2007}

The 2007 trials were performed in the same grain bins with the same maize from the two previous year ozonation trials. The target ozone concentration of $50 \mathrm{ppm}$ in the plenum was reached in less than two days $(39 \mathrm{~h})$ for Bin A and $\mathrm{C}$ and was subsequently held for five days (fig. 6). For Bin B it took almost three days $(63 \mathrm{~h})$ to reach $50 \mathrm{ppm}$ and treatment was continued for four more days. The treatment in all three bins was interrupted due to a power outage on 18 June for $12 \mathrm{~h}$. Therefore, Bin B was treated an extra day to offset the $12 \mathrm{~h}$ power shutdown. Bins $\mathrm{A}$ and $\mathrm{C}$ were held for two extra days at $50 \mathrm{ppm}$ (Phase 2) to assure the same end date as for Bin B. As in 2005 and 2006, the ozonated grain bins were aerated between summer 2006 and 2007, which resulted in $39 \mathrm{~h}$ (Bins A and C) and $63 \mathrm{~h}$ (Bin B) of Phase 1 passivation. For Bins A and $\mathrm{C}$ this was about half of what was observed in 2006, and about the same for Bin B.

Ozone concentration in the headspace for all three bins exceeded over $50 \mathrm{ppm}$ within $24 \mathrm{~h}$ of treatment start. Bins $\mathrm{A}$ and $\mathrm{C}$ had a similar pattern of ozone concentration averaging a difference of $50 \mathrm{ppm}$. This was slightly less than in 2006 but again should have been better regulated during the experiment.

Insect mortality for all bins was $100 \%$ for both MW and RFB (table 1). The insect bioassays in the control bin had an insect mortality average of $6 \%$ for both insect species. This verifies that no ambient conditions or other pest control treatments affected insect mortality by ozone treatment. The CTPs reached for all treated bins were almost four times the minimum CTP value of 3,600 ppm-h. These high CTPs were caused by greater ozonation than would be required and point to the need for optimization around the minimum CTP. 


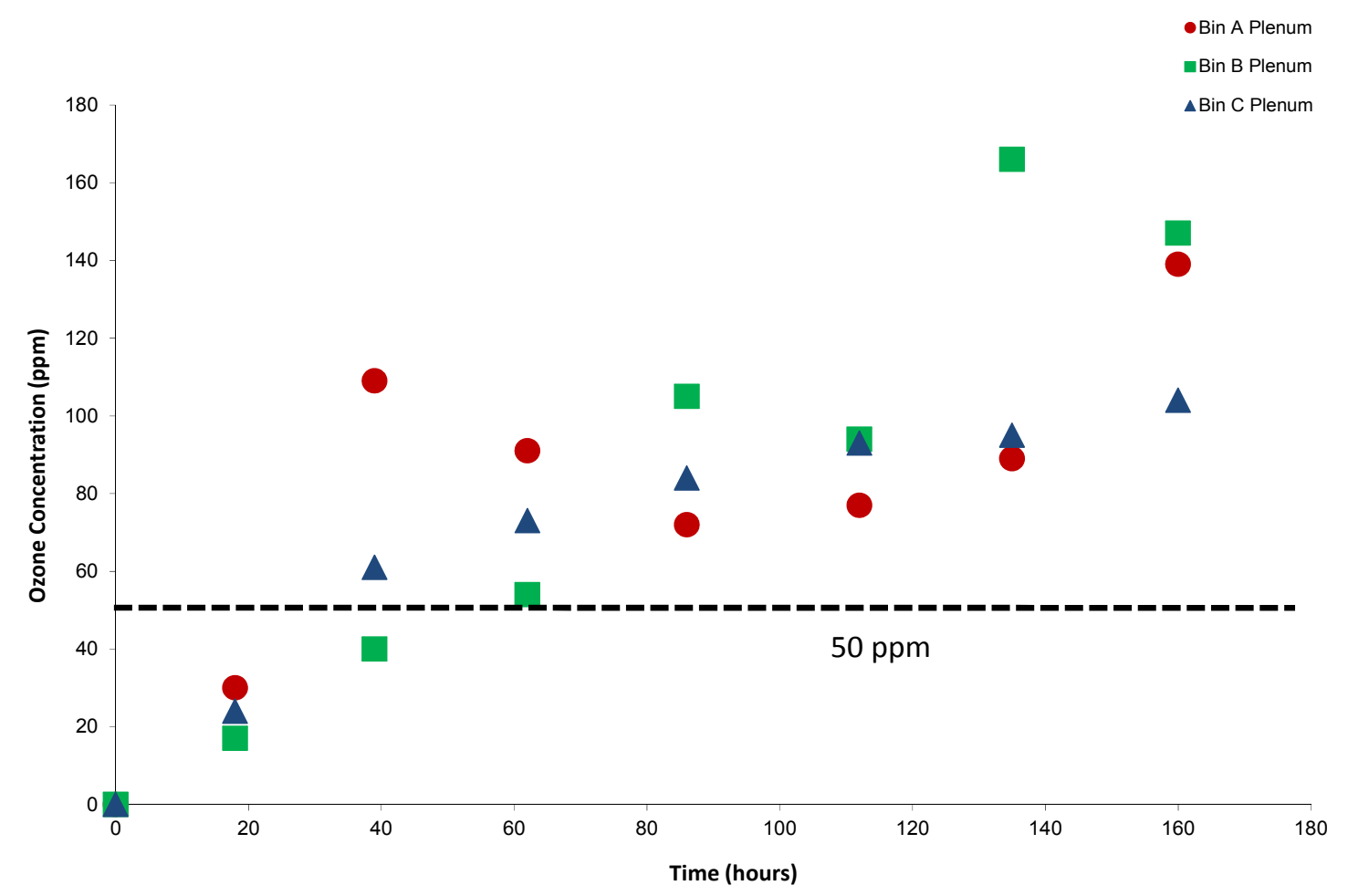

Figure 6. Ozone concentration profile in the plenum of PHERC Bins A, B, and C for ozonation of yellow maize in June 2007.

The sterilizing ozone effect produced by the previous treatments in 2005 and 2006 was reflected in the rapid achievement of Phase 2 in Bins A and C.

\section{Ozonation Trials with Yellow Conventional Maize at PHERC in 2008}

The 2008 trials were performed only in Bin B with the same maize from the three previous year's ozonation trials. The target ozone concentration of $50 \mathrm{ppm}$ (fig. 7) was reached in the plenum after two days (48 h) and was held subsequently for three days. Phase 2 was reached within a similar time as in the 2006 and 2007 trials. The ozone concentration in the headspace (fig. 7) showed an increase of more than $50 \mathrm{ppm}$ in the first day of treatment. It then reached the highest concentration of $232 \mathrm{ppm}$ and was maintained over $200 \mathrm{ppm}$ for the duration of the trial. These results differed from the pattern observed in Bin B for the trials in 2006, when the concentration never reached a value above $50 \mathrm{ppm}$, and for the trials in 2007 , when it

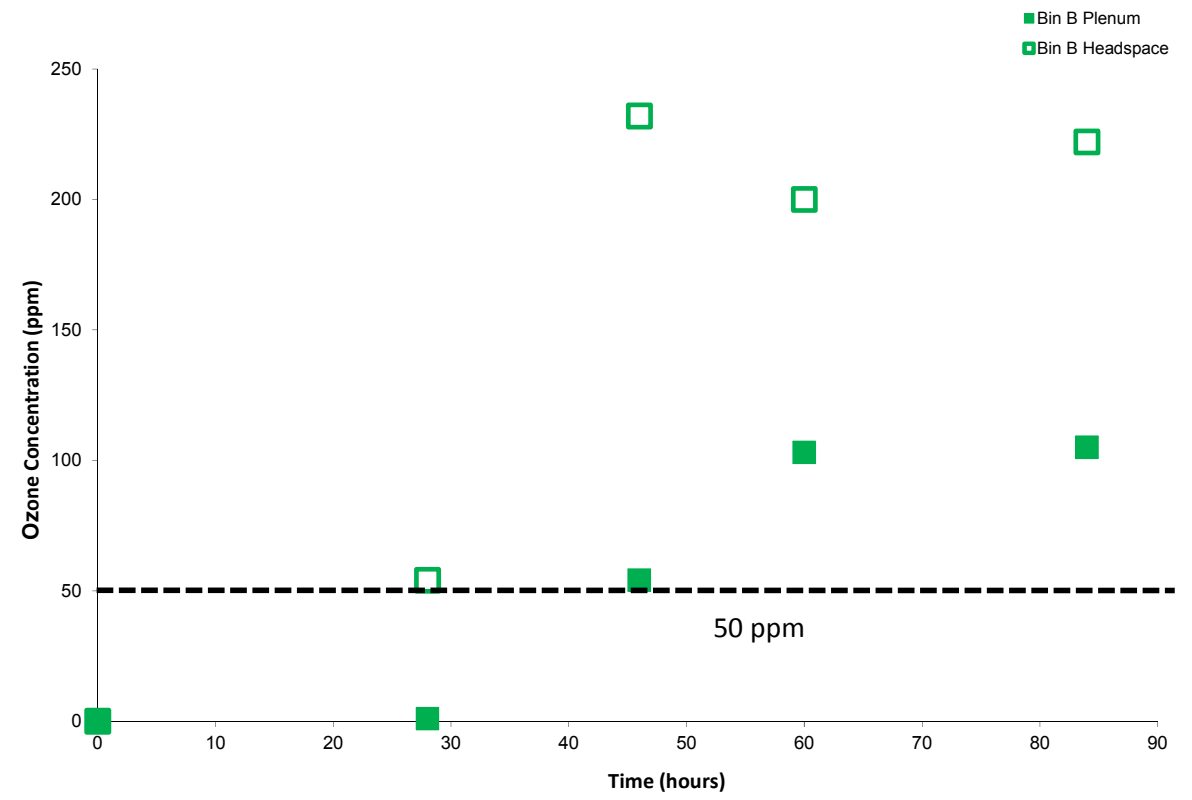

Figure 7. Ozone concentration profile in the plenum of PHERC Bin B for ozonation of yellow maize in October 2008. 
reached a high value near $60 \mathrm{ppm}$ and then decreased below $40 \mathrm{ppm}$ for the remainder of the trial. Given that only Bin B was ozonated in 2008, none of the ozone from the generator was diverted into other bins. After reaching Phase 2, ozone concentrations in the headspace and plenum were maintained constant until the treatment was finished.

Insect mortality for Bin B was 100\% for both MW and RFB (table 1). The insect bioassays in the control bins had an insect mortality of $5 \%$ and $6 \%$ for $\mathrm{MW}$ and RFB, respectively. The CTP reached was $8,500 \mathrm{ppm}-\mathrm{h}$ which was a similar value as in 2006 and about half the value from the 2007 trial.

Ozone proved to be an effective pest control technology to control stored grain adult insects (MW and RFB) of conventional yellow maize. No tests were performed on the yellow maize to verify whether ozone affected its end-use quality. However, previous research studies have shown that ozone treatment does not have a negative effect on end-use quality of conventional yellow maize in terms of its milling characteristics and intrinsic properties (Mendez et al., 2002), and no detrimental effect on seed germination (Strait, 1998).

\section{Summary of Results for Ozonation with Conventional Yellow Maize at PHERC}

During the trials from 2005 to 2008 , it was corroborated that as long as CTP is at least 3,600 ppm-h insect mortality for adult RFB and MW will be $100 \%$. The average ambient temperature (average between maximum and minimum values) during each trial from 2005 to 2008 was $22.4^{\circ} \mathrm{C}$ with a standard deviation of $0.6^{\circ} \mathrm{C}$. The average relative humidity was $73.8 \%$ with a standard deviation of $5.8 \%$. During each trial the consistency of the ambient temperature between day and night and the minimal variation of the relative humidity resulted in no effect on the insect mortality. During the treatment trials once the minimum air velocity of $0.03 \mathrm{~m} / \mathrm{s}$ (Mendez et al., 2003) was corrected by sizing up the fans in the treatment Bins A and B starting with the second ozonation in 2005, no difference in insect mortality was observed for the rest of the treatment trials. The results of insect mortality were comparable to those in laboratory experiment by Strait (1998) for both insect species, by Leesch (1998) and Pereira et al. (2008) for RFB, and field experimental trials by Kells et al. (2001) for both insect species and Bonjour et al. (2008) for RFB. At the same time, these results differed from the laboratory experiments by Erdman (1980) for RFB and Rozado et al. (2008) for both insect species where $100 \%$ insect mortality was reached with CTP well below 3,600 ppm-h. However, those experiments did not use grain in their bioassays which allowed the ozone to react with the insects at constant concentration and without the presence of other organic material that can interact with ozone reducing its efficacy.

The recirculation system used in all trials allowed for the re-usage of residual ozone after it had passed through the grain mass during Phase 2. This avoided exhausting any excess ozone into the environment and optimized its utilization. It was a similar setup as was used by Kells et al. (2001) and Hardin et al. (2010), but the effect and savings were not quantified.

\section{Ozonation Trials WITH POPCORN IN 2005 AND 2006}

The trials at the popcorn storage and processing facility were conducted during two consecutive storage seasons in July 2005 and 2006. In the 2005 trial, the results for the stored product insect bioassays located $0.6 \mathrm{~m}$ below the grain surface showed 100\% kill for MW and RFB, while the control insect bioassays showed almost 100\% insect survival. The trial had to be stopped after nearly 12 days of treatment before a $50 \mathrm{ppm}$ concentration could be achieved in the plenum due to the lack of airflow from the fan and ozone producing capacity of the generator. Only trace amounts of ozone around $1 \mathrm{ppm}$ were detected in the plenum. Thus, the insect bioassays located in the plenum showed no mortality. Unfortunately, the fan that drew the ozonated air down through the popcorn bulk and recirculated it back into the headspace was undersized $0.75 \mathrm{~kW}(1 \mathrm{hp})$ and did not achieve the minimum air velocity of $0.03 \mathrm{~m} / \mathrm{s}$. By the time a system redesign could be completed, the weather conditions had become much warmer and the facility manager stopped the ozonation treatment for fear of warming up the popcorn above safe storage conditions (i.e., grain temperature higher than $18^{\circ} \mathrm{C}$ ).

Necessary design modifications were made in 2006 to achieve successful ozonation treatment of popcorn at this facility by using a higher capacity $7.5 \mathrm{~kW}(10 \mathrm{hp})$ centrifugal fan which achieved an air velocity of $0.022 \mathrm{~m} / \mathrm{s}$ which was about $10 \%$ higher than the minimum air velocity of $0.02 \mathrm{~m} / \mathrm{s}$ needed for proper ozonation during Phase 2 (Kells et al., 2001). Due to physical constraints of a taller bin, an exhaust system blowing excess ozone into the plenum of a nearby bin (see fig. 2) was installed instead of a recirculation system. Both bins were connected by a $0.61 \mathrm{~m}\left(24 \frac{3}{8}\right.$ in. $)$ diameter flexible duct from a nonoperating axial fan on the treatment bin to a centrifugal fan on the neighboring bin that was operated to draw air through the popcorn mass and exhaust ozone into the bottom of the second bin. Therefore, in this trial, three bins were used (ozonated, exhaust, and control bins). Based on lessons learned during the 2005 trial, the eave opening of the ozonated bin was sealed using fumigation tape to eliminate ozone leakage to the environment and achieve more uniform airflow distribution across the grain surface.

In the trial, the target ozone concentration of $50 \mathrm{ppm}$ in the plenum was not reached due to the lack of sufficient ozone producing capacity of the generator for a relatively larger size bin. Therefore, a CTP of 3,600 ppm-h in the plenum was used to adjust the ozonation process over a longer period of time using a steady-state exhaust ozone concentration of $25 \mathrm{ppm}$ (fig. 8). When the CTP reached $3,600 \mathrm{ppm}-\mathrm{h}$ after 6 days, ozonation was stopped. Given that $25 \mathrm{ppm}$ in the plenum exhaust became the de facto steady-state ozone concentration after 3 days, that period was considered as Phase 1 and was not accounted for in the CTP calculation. Therefore, only the 6 days of Phase 2 were taken into account to reach the CTP of 3,600 ppm-h.

The results for insect mortality for RFB and MW placed $0.6 \mathrm{~m}$ below the grain surface and in the plenum were $100 \%$. These were the same results as in previous ozonation trials with conventional yellow maize at $50 \mathrm{ppm}$ 


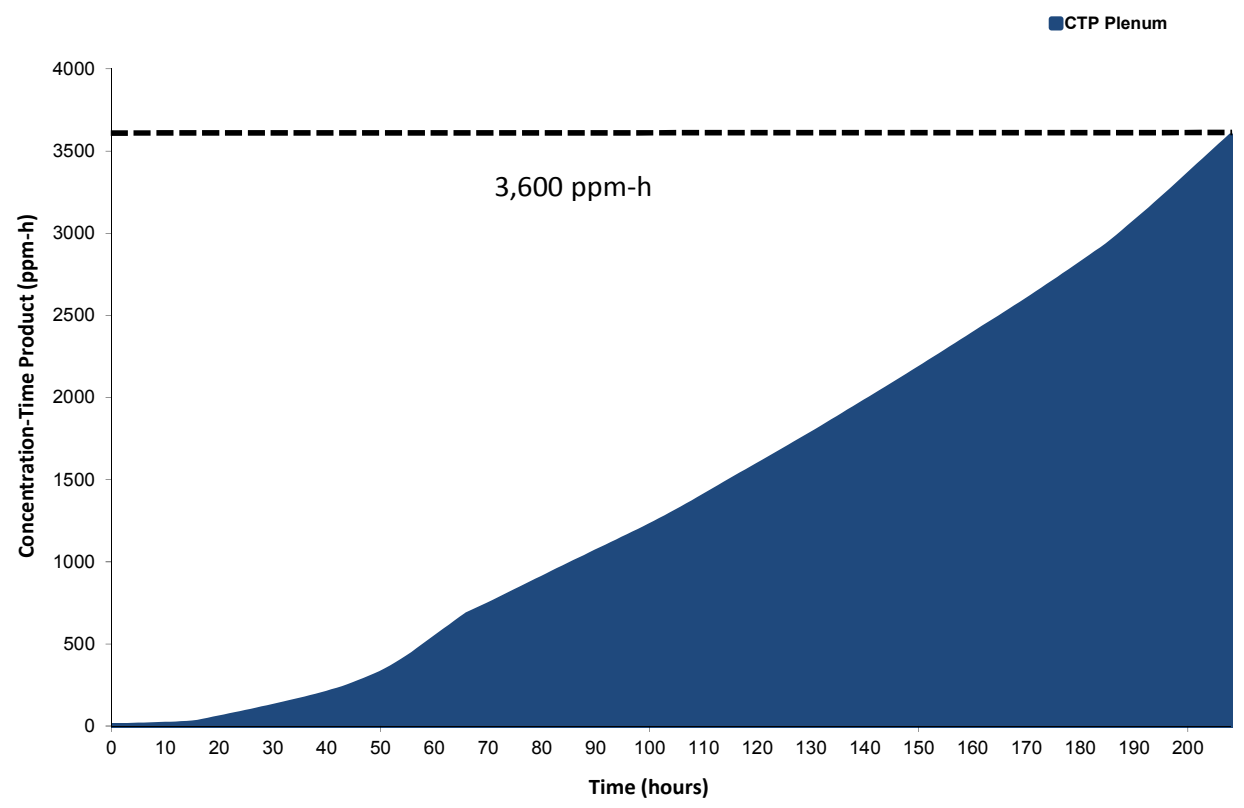

Figure 8. Ozone concentration-time product (CTP) at plenum of popcorn facility's bin for the ozonation of popcorn in July 2006.

for three days. Therefore, the results showed that a CTP of $3,600 \mathrm{ppm}-\mathrm{h}$ can be used to achieve $100 \%$ insect control (table 2) in grain storage structures when the $50 \mathrm{ppm}$ target concentration cannot be reached due to a lack of ozone producing capacity. Similar results were obtained by Kells et al. (2001) with $91 \%$ and $94 \%$ insect mortality for RFB and MW, respectively, by ozonating at $25 \mathrm{ppm}$ for 5 days $(120 \mathrm{~h})$ using a CTP of $3,000 \mathrm{ppm}-\mathrm{h}$. The mortality in the control bin had an average of $4 \%$ for RFB and 3\% for MW. Insect bioassays were also placed at optimal conditions in an incubator with a temperature of $28^{\circ} \mathrm{C}$ and a relative humidity of $65 \%$. Insect mortality was $4 \%$ for RFB and $4 \%$ for MW. Therefore, based on the mortality results of the control bin and incubator with optimal conditions, no other effects such as weather conditions, cannibalism among

Table 2. Insect mortality (\%) in bioassays of maize weevil (MW) and red flour beetle (RFB) placed in the plenum, and ozone concentrationtime product (CTP) during ozonation of popcorn bin (A), in the control bin, and in a lab incubation in July 2006.

\begin{tabular}{|c|c|c|c|c|c|}
\hline & \multicolumn{5}{|c|}{ Insect Mortality (\%) } \\
\hline & \multicolumn{2}{|l|}{ MW } & \multicolumn{2}{|l|}{ RFB } & \multirow{3}{*}{$\begin{array}{c}\text { CTP reached } \\
\text { in Plenum } \\
(\mathrm{ppm}-\mathrm{h})\end{array}$} \\
\hline & $0.6 \mathrm{M}$ below & & $0.6 \mathrm{M}$ below & & \\
\hline Bin & Grain Surface & Plenum & Grain Surface & Plenum & \\
\hline $\mathrm{A}$ & 100 & 100 & 100 & 100 & 3,600 \\
\hline Control & $4 \pm 1$ & $4 \pm 1$ & $3 \pm 1$ & $3 \pm 1$ & 0 \\
\hline Optimal & $1 \pm 1$ & $1 \pm 1$ & $1 \pm 1$ & $1 \pm 1$ & 0 \\
\hline
\end{tabular}

a] Optimal conditions were developed inside an incubator at $28^{\circ} \mathrm{C}$ and $65 \%$ relative humidity. insects, or other pest control treatments affected the ozone treatment in the popcorn bin. Ozone CTP of 3,600 ppm-h will allow for the use of current ozone generators in larger bins. However, extending the ozone exposure time of the grain to achieve a needed CTP will cause higher energy consumption of the generator, and a greater potential for shrink loss below desirable levels or for moisture addition that could cause grain spoilage.

The results for the first emergence progeny count for RFB showed $100 \%$ suppression after 28 day counts. Similar results for RFB were observed by Bonjour et al. (2008) after treatment of wheat with 4,800 ppm-h. For MW, the trial results showed that the first emergence progeny count after 28 days was four insects. No explanation was given, but most likely adult MW laid eggs inside the kernels before the ozone concentration reached lethal doses. Therefore, it can be assumed that the eggs survived because ozone does not penetrate the kernel's pericarp.

Popcorn quality was measured by popcorn facility personnel (table 3). The quality parameter of Metric Weight Volume Tester (MWVT) measured before and after ozonation treatment showed no difference between them. At the same time, moisture content did not vary as a result of treatment. The quality parameters of kernel count (KC) measured after ozonation did not show any difference when compared to the quality standards required by the

Table 3. Popcorn quality tests performed on samples by staff of the popcorn facility in 2006 .

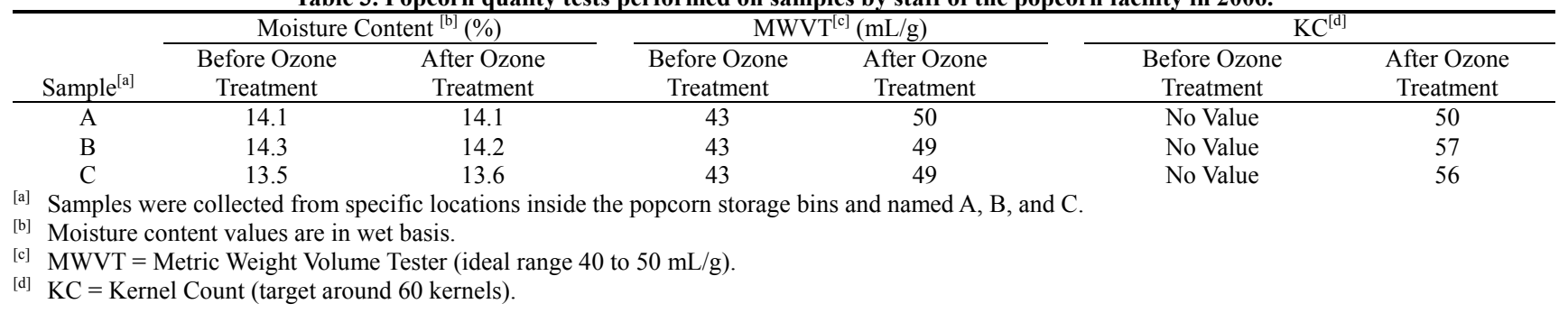


processing company. Mendez et al. (2003) after a laboratory ozonation with a CTP of 3,600 ppm-h reported a discoloration in the kernels probably caused by nitric acid formed during ozonation. This was not observed during the field trials. Also, Mendez et al. (2003) reported a slight reduction in popping volume, most likely due to the reduction of moisture content during treatment, which was not the case during the 2006 field trial.

\section{CONCLUSiOnS}

Overall, the results for the fixed bed ozonation treatment trials showed the efficacy of ozone on adult stored product insect mortality in yellow maize and popcorn without affecting its end-use quality. The specific conclusions of this study are:

- The CTP of 3,600 ppm-h to achieve $100 \%$ insect mortality using ozonation was confirmed for adult MW and RFB in fixed bed ozonation field trials.

- The two phases of ozonation treatment were confirmed with Phase 1 (sterilization or passivation) completed when a steady-state exhaust ozone concentration (e.g., 25 or $50 \mathrm{ppm}$ ) is reached and then maintained during Phase 2 (treatment stage) for a specific time (e.g., 3 or 6 days to achieve the desired CTP needed for $100 \%$ mortality of insects).

- The capacity of fixed bed ozonation systems is limited by the airflow capacity of the installed fan and the ozone producing capacity of the generator.

- The overall end-use quality of ozone-treated grain was not affected by fixed bed ozonation.

Based on the observations and design considerations with respect to future treatment trials, it was concluded that fixed bed ozonation treatment has several disadvantages which are:

- The initial ozonation treatment of a grain mass takes more time to complete than subsequent treatments of the same grain mass (as long as it is not moved and recontaminated with dust, etc.).

- Uniform distribution of ozone throughout the entire grain mass with currently available ozone generating capacity would take excessive time and could overexpose a grain bin structure (exposed wall and roof surfaces, loading and unloading equipment) to ozone that eventually may cause some deterioration (e.g., rusting) of exposed metal surfaces.

- Proper treatment of the grain mass will depend on the quantity of biological matter to be reacted with and the supply of ozone to complete the reaction process.

Therefore, in order to improve the treatment effect, a semi-continuous counter-flow ozonation treatment system may be conceived and designed based on findings on this study and previous research conducted on in-bin counterflow drying of grain and counterflow cooling of feed pellets (Maier and Bakker-Arkema, 1992; Marks et al., 1993). The primary reason for such an application is to ozonate grain at a faster rate based on the CTP of ozone required to remove off-odors from grain, eliminate microbial growth on grain kernels, and achieve $100 \%$ insect mortality in the bottom grain layer, which is removed after a predetermined treatment time.

\section{ACKNOWLEDGMENTS}

This research was part of a project funded by the USDA-CSREES Pest Management Alternatives Program (PMAP) and NC-IPM Program entitled "Demonstration Trials of Food Grains Ozonation - A New Chemical-Free Stored Product Pest Control Technology." The collaboration and participation of grain producers, handlers and processors as well as numerous equipment and service suppliers in this project across the United States has been greatly appreciated.

\section{REFERENCES}

ASABE Standards. 2008. S352.2: Moisture measurementUnground Grain and seeds. St. Joseph, Mich.: ASABE.

Bonjour, E. L., C. L. Jones, R. T. Noyes, J. Hardin, R. L. Beeby, D. A. Eltiste, and S. Decker. 2008. Efficacy of ozone against insect pests in wheat stored in steel grain bins. In Proc. $8^{\text {th }}$ International Conference on Controlled Atmosphere and Fumigation in Stored Products, 525-529. Chengdu, China: Sichuan Publishing Group.

Bonjour, E. L., G. P. Opit, J. Hardin, C. L. Jones, M. E. Payton, and R. L. Beeby. 2011. Efficacy of ozone fumigation against the major grain pests in stored wheat. J. Econ. Entomol. 104(1): 308-316.

EPA. 1999. Alternative Disinfectants and Oxidants Guidance Manual. Publication: 815-R-99014. Washington, D.C.: United States Environmental Protection Agency.

Erdman, H. E. 1980. Ozone toxicity during octonegy of two species of flour beetles, Tribolium confusum and T. castaneum. Environmental Entomology. 9(1): 16-17.

FDA. 2001. Secondary direct food additives permitted in food and human consumption. Federal Register 66, 33829-33830.

Graham, D. M. 1997. Use of ozone for food processing. Food Technology 51(6): 72-75.

Hansen, Lise S., P. Hansen, and K. V. Jensen. 2012. Lethal doses of ozone for control of all stages of internal and external feeders in stored products. Pest Manag. Sci.68(9): 1311-1316.

Hardin, J. A., C. L. Jones, E. L. Bonjour, R. T. Noyes, R. L. Beeby, D. A. Eltiste, and S. Decker. 2010. Ozone fumigation of stored grain: closed-loop recirculation and the rate of ozone consumption. J. Stored Prod. Res. 46(3): 149-154.

Holmstrup, M., J. G. Sorensen, L. H. Heckmann, S. Slotsbo, P. Hansen, and L. S. Hansen. 2011. Effects of ozone on gene expression and lipid peroxidation in adults and larvae of red flour beetle (Tribolium castaneum). J. Stored Prod. Res. 47(4): 378-384.

Kells, S. A., L. J. Mason, D. E. Maier, and C. P. Woloshuk. 2001. Efficacy and fumigation characteristics of ozone in stored maize. J. Stored Prod. Res. 37(4): 371-382.

Khadre, M. A., A. E. Youssef, and J. Kim. 2001. Microbiological aspects of ozone applications in food: A review. J. of Food Science 66(9): 1242-1252.

Leesch, J. G. 2002. The mortality of stored-product insects following exposure to gaseous ozone at high concentrations. In Proc $8^{\text {th }}$ International Working Conference on Stored Product Protection, 827-831. York, United Kingdom: CAB International.

Maier, D. E. and F. W. Bakker-Arkema. 1992. The counterflow cooling of feed pellets. J. of Agricultural Engineering Research 53(4): 305-320. 
Marks, B. P., D. E. Maier, and F. W. Bakker-Arkema. 1993. Optimization of a new in-bin counterflow maize drying system. Trans. ASABE 36(2): 529-534.

McClurkin, J. D. 2009. Control of stored grain fungi and off-odors with ozone in a grain treatment system. MS thesis. West Lafayette, Ind.: Purdue University, Department of Agricultural and Biological Engineering.

McDonough, M. X., C. A. Campabadal, L. J. Mason, A. Denvir, and C. P. Woloshuk. 2011a. Ozone application in a modified screw conveyor to treat grain for insect pests, fungal contaminants, and mycotoxins. J. Stored Prod. Res. 47(3): 249-254.

McDonough, M. X., L. J. Mason, and C. P. Woloshuk. 2011b. Susceptibility of stored product insects to high concentrations of ozone at different exposure intervals. J. Stored Prod. Res. 47(4): 306-310.

Mendez, F, D. E. Maier, L. J. Mason, and C. P. Woloshuk. 2003. Penetration of ozone into columns of stored grains and effects on chemical composition and processing performance. J. Stored Prod. Res. 39(1): 33-44.

Noyes, R., S. Navarro and, D. Armitage. 2002. Supplemental aeration systems. In The Mechanics and Physics of Modern Grain Aeration Management, 413-488. S. Navarro, and R. Noyes eds. Boca Raton, FL: CRC Press.
Pereira, A. M., L. R. A. Faroni, A. H. Sousa, W. M. I. Urruchi, and J. L. Paes. 2008. Influence of the grain temperature on the ozone toxicity to Tribolium Castaneum. Revista Brasileira de Engenharia Agricola e Ambiental. 12(5): 493-497.

Rozado, A. F., L.R. A. Faroni, W. M. I. Urruchi, R. N. C. Guedes, and J. L. Paes. Ozone application against Sitophilus zeamais and Tribolium Castaneum on stored maize. Revista Brasileira de Engenharia Agrícola e Ambiental. 12(3): 282-285.

Sousa, A. H., L. R. A. Faroni, R. N. C. Guedes, M. R. Tótola, and W. M. I. Urruchi. 2008. Ozone as a management alternative against Phosphine-resistance insect pests of stored products. $J$. Stored Prod. Res. 44(4): 379-385.

Strait, C.A. 1998. Efficacy of ozone to control insects and fungi in stored grain. MS thesis. West Lafayette, Ind.: Purdue University. Department of Entolomology.

UNEP. 1995. Montreal Protocol on substances that deplete the ozone layer. 1994 Report of the methyl bromide technical option committee, 1995 assessment. Kenya. Available at: http://ozone.unep.org/Assessment_Panels/TEAP/Reports/MBTO C/MBTOC94.pdf. Accessed 23 June 2011.

Ziegler, K. E. 2002. Popcorn. In Maize Chemistry and Technology, $2^{\text {nd }}$ Ed., 783-809. P. J. White and L. A. Johnson, eds. St. Paul, Minn.: American Association of Cereal Chemists. 